\title{
Spreader graft placement in endonasal rhinoplasty: Technique and a review of 100 cases
}

\author{
M Samaha MD FRCSC, A Rassouli MD
}

M Samaha, A Rassouli. Spreader graft placement in endonasal rhinoplasty: Technique and a review of 100 cases. Plast Surg 2015;23(4):252-254.

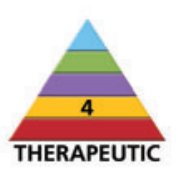

BACKGROUND: Spreader grafts are widely considered to be the mainstay of treatment for insufficient internal nasal valve and are commonly placed preventively during rhinoplasty, after hump removal, to avoid middle vault collapse. Although the placement and suturing of spreader grafts in open rhinoplasty is fairly easy, their positioning and stabilization in endonasal rhinoplasty is associated with a learning curve.

METHODS: A review of the technique with tips for the novice surgeon is presented, particularly as pertains to correct placement. The technique can be used to insert spreader grafts irrespective of whether the nasal dorsum is addressed. Suturing is usually unnecessary. A retrospective review of 100 patients in whom spreader grafts were placed was undertaken to evaluate complications such as poor placement, displacement or other complications.

RESULTS: Although there is a learning curve to ensure the dorsal mucosal attachment is maintained while developing the pocket sufficiently dorsally for proper graft placement, the technique is easy to learn, effective, quick and technically simple to perform. Of 100 patients, three had a cartilaginous dorsal spur as the cephalic edge of the graft became visible. One patient developed an ecchymosis along the dorsum that caused a hump that resolved in two months. There were no other aesthetic or functional complications. CONCLUSION: The endonasal placement technique provides for simple, safe and easy placement, as well as stabilization of spreader grafts during endonasal rhinoplasty, with few complications.

Key Words: Endonasal; Internal valve stenosis; Rhinoplasty; Spreader graft

$\mathrm{T}$ he internal nasal valve (INV) has the smallest cross-sectional area in the nasal passage and constitutes more than two-thirds of nasal airway resistance (1). The valve is delineated superiorly by the angle between the caudal margins of the upper lateral cartilages (ULCs) and septum, laterally by the inferior turbinate and inferiorly by floor of the nose (2). Narrowing or complete obliteration of the valve angle (between the septum and ULC) to $<15^{\circ}$ due to physical obstruction, collapse, septal deviation or synechiae increases the chance of subjective nasal obstruction $(3,4)$

The most common cause of iatrogenic narrowing of the valve angle is hump reduction at the time of rhinoplasty. In some patients, reduction of a hump causes an unstable open roof in the cartilaginous dorsum with poor or no support for the ULCs, and consequent middle vault collapse. While this is not a certainty in every patient, its occurrence is considered to be an aesthetic and functional complication. Risk factors, although not universally agreed on, include a visibly narrow middle vault preoperatively (Figure 1A), thin skin, short nasal bones and large dorsal hump. Aesthetically, postoperative middle vault collapse is visible as a narrowing of the middle one-third of the nose, which may not be obviously apparent in patients with thick skin. In severe cases, the typical 'inverted V' deformity is seen (Figure 1B). Functionally, even a modest degree of narrowing of the valve angle can cause significant symptoms of nasal obstruction.

Spreader grafts have been shown to be effective for the treatment of nasal obstruction, usually post-rhinoplasty, or its prevention during rhinoplasty $(5,6)$. As a result, spreader grafts are widely used

\author{
L'implantation d'écarteurs en cas de rhinoplastie \\ endonasale : la technique et une analyse de 100 cas
}

HISTORIQUE : Les greffes d'écarteur sont largement considérées comme le pilier du traitement lorsque la valve nasale interne est trop étroite. Elles sont souvent implantées de manière préventive pendant la rhinoplastie, pour éviter l'affaissement du septum après la correction d'une bosse. Même si l'implantation et la suture des écarteurs sont plutôt simples lors d'une rhinoplastie ouverte, leur mise en position et leur stabilisation s'associent à une courbe d'apprentissage pour la rhinoplastie endonasale.

MÉTHODOLOGIE : Une analyse de la technique avec des pinces pour le chirurgien novice est présentée, particulièrement pour garantir une bonne implantation. On peut utiliser la technique pour implanter des écarteurs, même si on ne touche pas l'arête du nez. En général, les sutures sont inutiles. Les chercheurs ont entrepris une analyse rétrospective de 100 patients qui se sont fait implanter des écarteurs, afin d'évaluer des complications comme une mauvaise implantation, un déplacement ou d'autres problèmes.

RÉSULTATS : Même s'il y a une courbe d'apprentissage pour s'assurer que la muqueuse de l'arête du nez est bien rattachée et développer suffisamment la poche de l'arête pour bien implanter la greffe, la technique est facile à apprendre, efficace, rapide et simple sur le plan technique. Sur les 100 patients, trois ont présenté un éperon cartilagineux tandis que le bord céphalique de la greffe devenait visible. Un patient a présenté une ecchymose le long de l'arête du nez, laquelle a causé une bosse qui a disparu au bout de deux mois. Aucune autre complication n'a touché l'esthétisme ou la fonction du nez.

CONCLUSION : La technique d'implantation endonasale est simple, sécuritaire et facile. Elle permet de bien stabiliser les écarteurs pendant la rhinoplastie endonasale et provoque peu de complications.

during rhinoplasty surgery, particularly as a preventive measure after hump reduction to maintain a wide nasal valve angle.

To be effective, spreader grafts must be precisely positioned between the dorsal septum and the ULC while spanning the length of the latter. Placement too high will cause esthetic dorsal irregularities and placement too low along the septum will be ineffective at supporting the ULC. In addition, too cephalic a position will also cause 'spreading' of the nasal bones after osteotomies, thereby widening the pyramid. When voluntarily performed, this is referred to as an 'extended spreader' graft. A graft placed too caudally may widen the tip. Placement and fixation of spreader graft must, therefore, be precise.

Placement of spreader grafts in open rhinoplasty is a relatively simple task. However, the use of the endonasal technique makes positioning and stabilization of spreader grafts a technical challenge. In particular, suturing the grafts for stabilization within the small space available requires technical prowess and patience and may be frustrating even for the experienced rhinoplasty surgeon. The endonasal placement technique, described by Sheen (7) is simple and effective, although it does require precision. Indeed the novice surgeon may find it difficult to develop the pocket in the exact position desired for graft placement and a learning curve results in a certain number of poorly placed grafts before comfort with the technique is acquired. We anticipate that the tips outlined in the present report will help shorten this learning curve.

Telephone 514-731-2525, e-mail mark_samaha@mcgill.ca 


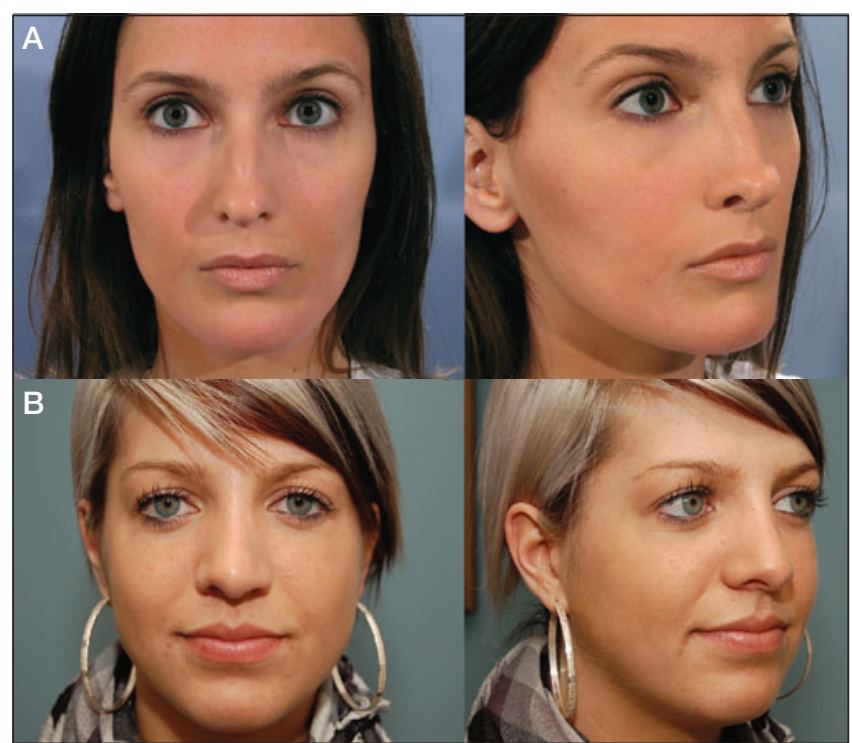

Figure 1) A Example of narrow middle vault with risk of collapse or stenosis postsurgery. B Inverted V deformity most apparent on the patient's right side

\section{METHODOLOGY}

Patient selection

A retrospective chart review of 100 patients who underwent spreader graft placement alone or in the context of rhinoplasty surgery was performed. Information collected included demographics, unilateral or bilateral grafts, length of follow-up and postoperative complications (nasal obstruction, esthetic irregularity resulting from the graft). Consent was obtained for photo publication.

\section{Surgical technique}

During endonasal rhinoplasty, cartilage is harvested, usually from the septum, using a limited Killian incision that stops $1.5 \mathrm{~cm}$ to $2 \mathrm{~cm}$ before reaching the dorsal septum to maintain the mucosa over the dorsal septum intact and attached to the septal cartilage. If a septoplasty is to be performed for functional reasons, the cartilage is resected at that time. Otherwise, a rectangular portion of quadrangular cartilage is resected when the procedure reaches the point of spreader graft placement, which, in our practice, is usually before performing osteotomies. The spreader grafts are cut and shaped on a metal plate on a back table. The usual size is approximately $2 \mathrm{~cm}$ to $2.5 \mathrm{~cm} \times 5 \mathrm{~mm}$ with thickness being approximately $2 \mathrm{~mm}$.

If the dorsum is reduced, as it is in most of our primary cases, an incremental reduction of the cartilaginous dorsum is performed until the desired level is reached. The mucosa between the ULC and septum is preserved intact. Attention is devoted to avoid violation of mucosal attachment at the most dorsal aspect of septum during hump reduction maneuvers. Our fixation of the grafts is dependent on the creation of a tight submucoperichondrium pocket at the angle of the INV. Hence, maintaining the attachment of septal mucosa to the dorsal septum is paramount to the creation of such a closed pocket. If this attachment is disrupted, the pocket will 'open' dorsally and suture fixation will be required.

A stab incision of approximately $2 \mathrm{~mm}$ to $3 \mathrm{~mm}$ is made using a No. 15 scalpel blade through the mucosa and perichondrium, and placed $2 \mathrm{~mm}$ caudal to the caudal edge of the ULC (Figure 2). The incision is approximately $3 \mathrm{~mm}$ to allow for the placement of the graft.

A submucoperichondrial pocket is created using a $2 \mathrm{~mm}$ curved Lempert elevator (Instrumentarium, Terrebone, Canada) through blunt dissection approximately $2 \mathrm{~cm}$ to $3 \mathrm{~cm}$ long to the cephalic margin of the ULC. Great care must be taken to ensure the proper angle of dissection as the pocket is advanced, and to maintain the attachment of the mucoperichondrium to the dorsal septum.

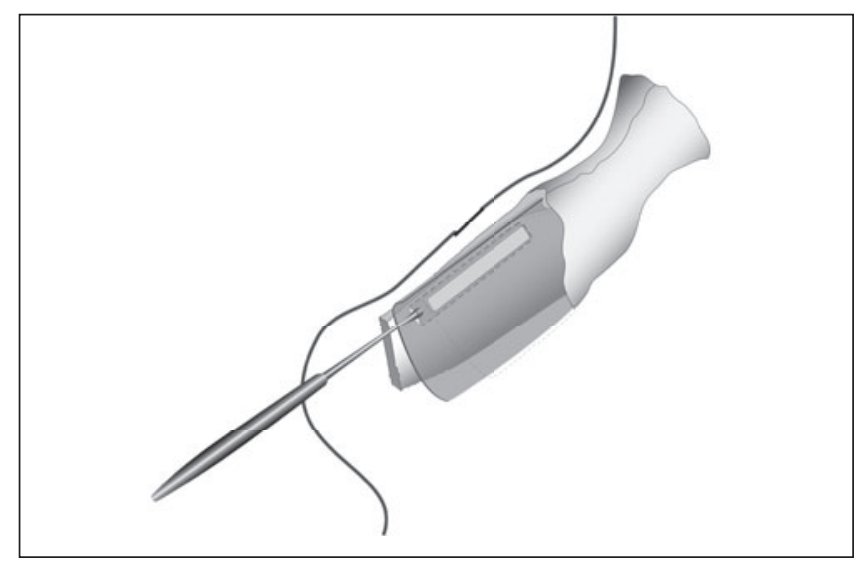

Figure 2) Creation of the submucoperichondrial pocket. A submucoperichondrial pocket is created using a $2 \mathrm{~mm}$ curved Lempert elevator. Care is taken not to disrupt the most dorsal attachments of septal mucosa as shown by the superior dotted line

After a secure and adequate pocket is created, the grafts are then placed using Adson-Brown forceps (Figure 3). Should there be significant resistance while placing the graft, the graft should be removed and the pocket enlarged slightly to accommodate the graft or the graft resized if appropriate. Because the pocket is made a few millimeters longer than the graft (incision is made $2 \mathrm{~mm}$ caudal to the caudal edge of ULC), once the graft is successfully placed, the edges of the stab incision will re-approximate easily. No suture closure is needed.

\section{RESULTS}

All 100 cases were performed using an endonasal approach. The mean age was 31.2 years, with $83 \%$ females. Ninety-four percent of patients had bilateral spreader grafts and $92 \%$ had spreader grafts at the time of rhinoplasty. Of these, 29\% (27 patients) were revision rhinoplasty cases. The remaining $8 \%$ had spreader grafts only and without other manoeuvres, following previous rhinoplasty and middle vault collapse. The mean follow-up was 9.3 months (Table 1).

Three patients had a dorsal irregularity on the left side at the cephalic edge of the graft. This required shaving to address the aesthetic concern, although there was no functional consequence. One patient had spreader grafts placed following middle vault collapse following rhinoplasty performed elsewhere 12 years previously. Following the procedure, a hyperemic prominence was noted at the dorsum, which resolved slowly, taking two months to completely disappear. There were no other complications.

No patient reported nasal obstruction and $97 \%$ reported improved nasal breathing. These 97 patients included the eight patients who had spreader grafts alone (Figure 4). The 3\% not reporting improvement were all patients who consulted for aesthetic rhinoplasty and who expressed a partial limitation in their airway preoperatively. Postoperatively, this symptom had neither improved nor worsened. All were females.

\section{DISCUSSION}

Spreader graft placement has become the preferred method of INV reconstruction since its introduction in the 1980s. However, placement and fixation can be challenging in closed rhinoplasty.

As described above, the tight submucoperichondrial pocket is the key to proper fixation of the grafts. Figure 5 illustrates the importance of placement and dissection of the pocket. Attention must be devoted to maintain the small dorsal attachment throughout the length of the pocket while ensuring the close proximity to the dorsal septum. A helpful guide is to visualize, using an Aufricht elevator, the septal dorsum and the mucosa attached to it as the pocket is being developed. This enables the surgeon to visualize the elevator under the mucosa to insure the pocket is sufficiently dorsal while maintaining an attachment between the mucosa and dorsal septum. This is similar to septal 


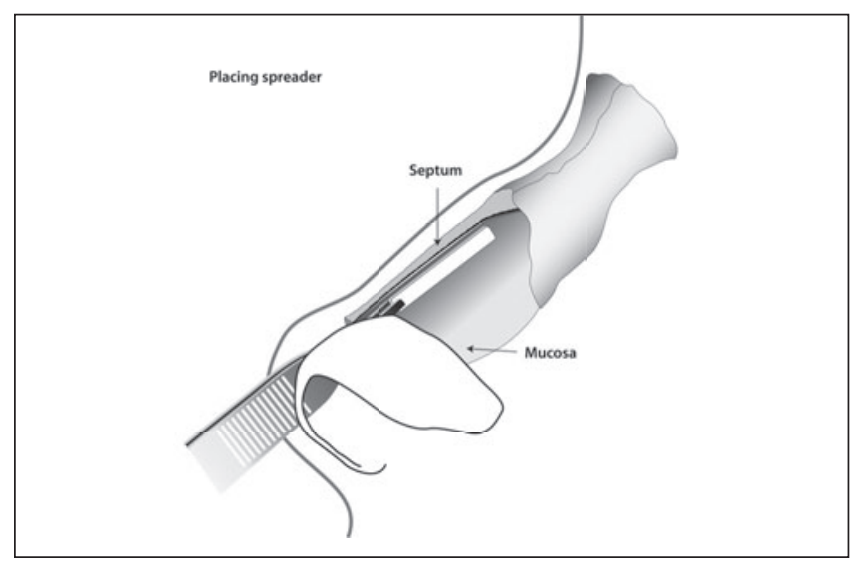

Figure 3) Placement of spreader graft into submucoperichondrial pocket. Subsequent to the creation of the pocket, the preshaped grafts are placed into the tight pockets using Adson-Brown forceps

TABLE 1

\section{Patient cohort $(n=100)$}

\begin{tabular}{ll}
\hline Characteristic & \\
\hline Age, years, mean & 31.2 \\
Follow-up period, months, mean & 9.3 \\
Sex, female/male & $83 / 17$ \\
Side, bilateral/unilateral & $94 / 6$ \\
Associated procedure & \\
$\quad$ With rhinoplasty & 92 \\
Spreader graft only & 8 \\
\hline
\end{tabular}

Data presented as \% unless otherwise indicated

mucoperichondrium elevation during sepoplasty, sometimes referred to as 'mouse under the rug'.

The dorsal irregularity that occurred in three patients was due to poor orientation of pocket development The surgeon's angle, as the elevator is inserted is usually dorsal, particularly on the left for a righthanded surgeon. Therefore, it is probable that the pocket opened dorsally at its cephalic aspect, allowing the graft to protrude through this opening. This highlights the importance of visualizing the dorsal septal cartilage and mucosa as the pocket is being developed to insure the elevation is sufficiently dorsal and along the septal dorsum.

Another method to secure the grafts is to suture them as is performed in open rhinoplasty. This involves elevation of the dorsal mucosa, graft placement and suturing to the septal cartilage. We have also used this method (8), although it is technically more demanding. However, this is a good option, particularly for novice surgeons in case the dorsal mucosal attachment to the septum is violated during pocket development.

A helpful way of assessing the positioning of the pocket developed as one is acquiring the technique is to proceed with developing the pocket, placement of the graft, followed by elevation of the dorsal mucosa to assess the position of the graft. This learning, self-assessment approach is ideally used in cadaver specimens if available. However, it can also be performed intraoperatively. Frequently, the surgeon will initially note that there is a tendency to develop the pocket too low on the septum.

Although the proportion of patients reporting an improvement of their nasal airway postoperatively is high (97\%), it is not possible to attribute that to spreader grafts alone because there can be other contributing factors, including an overall change in nasal dimensions and anatomy due to the other modifications performed on the nose, as well as concomitant procedures such as septoplasty and turbinoplasty. It is noteworthy, however, that the eight patients undergoing spreader grafts alone all noted an improvement in their nasal airway.

While this technique has existed for years, its use is not commonly adopted, largely due to the widespread training in and utilization of

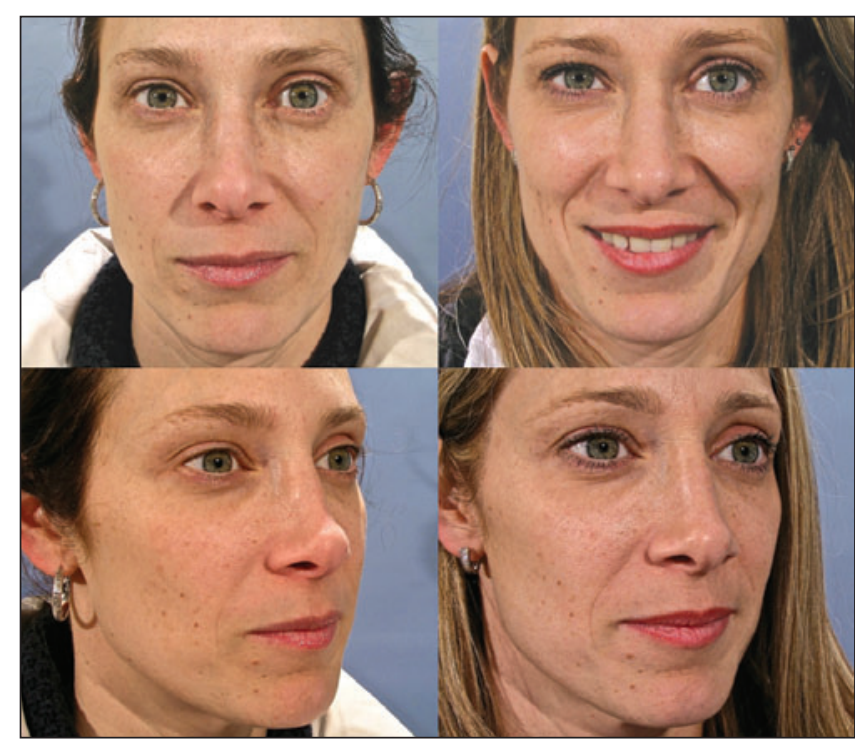

Figure 4) Spreader graft. Before (left) and after (right) photos in a patient with only spreader graft placement

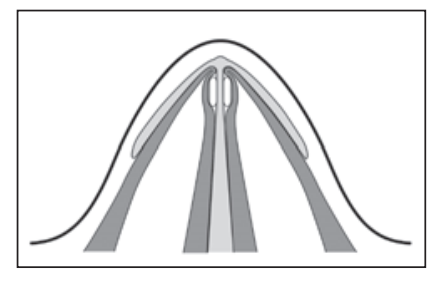

Figure 5) Basal view following placement of the spreader graft. As shown, thin mucoperichondrial attachments to the septal cartilage are kept intact dorsal to the pocket. This ensures proper fixation of the spreader graft at the internal nasal valve, with a sufficiently dorsal position to be effective

open rhinoplasty. However, revisiting the technique, its simplicity of execution, and its efficacy is worthwhile because it may help both novice and experienced surgeons to focally address a common functional issue in rhinoplasty, both preventively in primary rhinoplasty and therapeutically in revision cases.

\section{CONCLUSION}

Spreader graft placement in endonasal rhinoplasty is a simple, effective and efficient technique. The aspect of the technique associated with a learning curve is development of the pocket in the proper location while maintaining it intact.

\section{REFERENCES}

1. Wittkopf M, Wittkopf J, Ries WR. The diagnosis and treatment of nasal valve collapse. Curr Opin Otolaryngol Head Neck Surg 2008;16:10-3.

2. Yoo DB, Jen A. Endonasal placement of spreader grafts: Experience in 41 consecutive patients. Arch Facial Plast Surg 2012;14:318-22.

3. Reiffel AJ, Cross KJ, Spinelli HM. Nasal spreader grafts: A comparison of medpor to autologous tissue reconstruction. Ann Plast Surg 2011;66:24-8.

4. Cho GS, Kim JH, Jang YJ. Correlation of nasal obstruction with nasal cross-sectional area measured by computed tomography in patients with nasal septal deviation. Ann Otol Rhinol Laryngol 2012;121:239-45.

5. de Pochat VD, Alonso N, Mendes RRS, Cunha MS, Menezes JVL. Nasal patency after open rhinoplasty with spreader grafts.

J Plast Reconstr Aesthet Surg 2012;65:732-8.

6. Bracaglia R, Gentileschi S, D'Ettorre M, Tambasco D. A technique to make spreader graft fixation easier. Plast Reconstr Surg. 2012;129:857e-859e.

7. 7. Sheen JH (1984). Spreader graft: A method of reconstructing the roof of the middle nasal vault following rhinoplasty. Plast Reconstr Surg 1984;73:230-7.

8. Byrd HS, Salomon J, Flood J. Correction of the crooked nose. Plast Reconstr Surg 1998;102:2148-57. 